\title{
Sensitive detection of hydrocarbon gases using electrochemically Pd-modified ZnO chemiresistors
}

\author{
Elena Dilonardo ${ }^{* 1,2}$, Michele Penza ${ }^{*}$, Marco Alvisi ${ }^{3}$, Gennaro Cassano ${ }^{3}$, \\ Cinzia Di Franco ${ }^{4}$, Francesco Palmisano ${ }^{1}$, Luisa Torsi ${ }^{1}$ and Nicola Cioffi ${ }^{* 1}$
}

Open Access

\author{
Full Research Paper \\ Address: \\ ${ }^{1}$ Department of Chemistry, Università degli Studi di Bari Aldo Moro, \\ Bari, Italy, ${ }^{2}$ Department of Electrotechnics and Electronics, \\ Politecnico di Bari, Bari, Italy, ${ }^{3}$ Italian National Agency for New \\ Technologies, Energy and Sustainable Economic Development \\ (ENEA), Laboratory Functional Materials and Technologies for \\ Sustainable Applications - Brindisi Research Center, Brindisi, Italy \\ and ${ }^{4}$ CNR-IFN Bari, Bari, Italy \\ Email: \\ Elena Dilonardo* - elena.dilonardo@uniba.it; Michele Penza* - \\ michele.penza@enea.it; Nicola Cioffi - nicola.cioffi@uniba.it \\ * Corresponding author \\ Keywords: \\ chemiresistive gas sensor; electrosynthesis; hydrocarbon gas sensor; \\ $\mathrm{Pd}$-modified $\mathrm{ZnO}$; $\mathrm{ZnO}$ nanorods
}

Beilstein J. Nanotechnol. 2017, 8, 82-90. doi:10.3762/bjnano.8.9

Received: 22 August 2016

Accepted: 20 December 2016

Published: 10 January 2017

This article is part of the Thematic Series "Functional materials for environmental sensors and energy systems".

Associate Editor: N. Motta

(C) 2017 Dilonardo et al.; licensee Beilstein-Institut. License and terms: see end of document.

\begin{abstract}
Pristine and electrochemically Pd-modified $\mathrm{ZnO}$ nanorods ( $\mathrm{ZnO} \mathrm{NRs}$ ) were proposed as active sensing layers in chemiresistive gas sensors for hydrocarbon (HC) gas detection (e.g., $\mathrm{CH}_{4}, \mathrm{C}_{3} \mathrm{H}_{8}, \mathrm{C}_{4} \mathrm{H}_{10}$ ). The presence of Pd nanoparticles (NPs) on the surface of $\mathrm{ZnO} \mathrm{NRs}$, obtained after the thermal treatment at $550{ }^{\circ} \mathrm{C}$, was revealed by morphological and surface chemical analyses, using scanning electron microscopy and X-ray photoelectron spectroscopy, respectively. The effect of the Pd catalyst on the performance of the $\mathrm{ZnO}$-based gas sensor was evaluated by comparing the sensing results with those of pristine $\mathrm{ZnO} \mathrm{NRs}$, at an operating temperature of $300{ }^{\circ} \mathrm{C}$ and for various $\mathrm{HC}$ gas concentrations in the range of 30-1000 ppm. The Pd-modified ZnO NRs showed a higher selectivity and sensitivity compared to pristine ZnO NRs. The mean sensitivity of Pd-modified ZnO NRs towards the analyzed HCs gases increased with the length of the hydrocarbon chain of the target gas molecule. Finally, the evaluation of the selectivity revealed that the presence or the absence of metal nanoparticles on $\mathrm{ZnO}$ NRs improves the selectivity in the detection of specific HCs gaseous molecules.
\end{abstract}

\section{Introduction}

Hydrocarbons (HCs) are molecules consisting of carbon and hydrogen atoms, and the gaseous species can be present in the atmosphere depending on their volatility or vapor pressure. As volatile molecules in the atmosphere, they are classified as volatile organic compounds (VOCs). The U.S. Environmental Protection Agency (EPA) defines a VOC as any carbonaceous 
compound of carbon that is involved in atmospheric photochemical reactions [1].

The presence of HCs in the atmosphere has either anthropogenic or natural sources. The former involve the emission of a great number of species and concern various industrial activities, mostly related to production, treatment, storage and combustion of fossil fuel. The natural sources produce a much smaller variety of $\mathrm{HC}$ species, indeed the major emitted $\mathrm{HC}$ gas is methane [1]. Therefore, it is clear that the detection and monitoring of gaseous HCs is fundamental for environmental protection [2,3]. The direct exposure to HCs can negatively affect the human health, from irritation of the respiratory system to cancer $[4,5]$. Therefore, the selective detection of particular gaseous HCs in a complex matrix is one of the challenges in gas detection for environmental monitoring.

In the last years, various techniques have been used for $\mathrm{HC}$ gas detection [6-9]. However, they still have some limitations such as the need for expensive instruments, time-consuming procedures, complicated pre-treatments and periodical maintenance [10-14]. Since a precise monitoring of HCs even at low concentrations can be beneficial to preserve the environment and human health, the improvement of cost-effective HCs gas sensors, including networked sensor-systems and new strategies for hydrocarbon sensing, is a matter of interest for the scientific community.

HCs gas sensors based on organic conducting polymers (such as polyaniline (PANI) [15,16], polypyrrole (PPy) [17] and polythiophene (PTh) [18]) and on carbon-based nanomaterials with desired functionality and conductivity (e.g., carbon nanotubes (CNTs) [19] and graphene [20]) exhibit a comparably good gas-sensing performance $[21,22]$. However, due to their high affinity toward $\mathrm{HCs}$ and low thermal stability, they are sometimes unstable and exhibit poor sensitivity [23,24]. In this context, metal oxides $\left(\mathrm{MO}_{x}\right)$ have been proposed as promising active sensing layers because of their advantageous properties such as good sensitivity under ambient conditions and easy preparation [25].

The fundamental process of the gas-sensing mechanism, holding the $\mathrm{MO}_{x}$-based sensing material at elevated temperatures above $300{ }^{\circ} \mathrm{C}$, is the reaction of the surrounding gases with the oxygen of the $\mathrm{MO}_{x}$ layer, causing changes in the surface potential and resistivity of the sensing material. The electrical resistance can increase or decrease, depending on the type of doping of $\mathrm{MO}_{x}$ (p-or n-type) and on the analyte gas. There are oxidizing gases, such as nitrogen oxide $\left(\mathrm{NO}_{2}\right)$, and ozone $\left(\mathrm{O}_{3}\right)$, and reducing gases such as carbon monoxide $(\mathrm{CO})$ and hydrocarbons (HCs) [26]. The magnitude of the variation of the electrical resistance gives a direct measure of the concentration of the analyte gas [25].

In the last decades, different nanostructured $\mathrm{MO}_{x}$-based gas sensors with improved performance in the $\mathrm{HC}$ gas detection were developed [27-37]. Among $\mathrm{MO}_{x}$ semiconductors, nanostructured $\mathrm{ZnO}$ is promising as sensing material in chemiresistive gas sensors, although its use still reveals some drawbacks related to its low selectivity, long response and recovery times, high power consumption, and poor stability over the time [38]. These limits can be overcome by functionalization of $\mathrm{ZnO}$ nanostructures with noble metal nanoparticles. Specifically, Pt and $\mathrm{Pd}$ are widely applied for monitoring explosive and toxic gases. The catalytic metals do not change the free energy of the reactions but lower the activation energy. The sensing response of $\mathrm{ZnO}$ towards most of the toxic gases in general, and towards HC gases in particular, can be improved by surface deposition of noble metals. Sivapunniyam et al. [39] have reported the improvement of $\mathrm{ZnO}$-nanorod-based $\mathrm{HC}$ gas sensing by doping the metal oxide with Pt nanoparticles. Gurav et al. [40] reported an improvement of $60 \%$ in the response towards LPG detection at an operating temperature of $498 \mathrm{~K}$ using $\mathrm{ZnO}$ nanorods functionalized by catalytic Pd NPs. Moreover, the $\mathrm{Pd}$-sensitized vertically aligned $\mathrm{ZnO}$ nanorods showed higher selectivity towards LPG than to $\mathrm{CO}_{2}$.

Most of the processes that, to date, have been developed to functionalize $\mathrm{MO}_{x}$ nanostructures with noble metal NPs $[32,41]$ are unique and effective, but, at the same time, also complex and time-consuming. Moreover, metal NPs deposited by these processes can undergo undesired clustering with the subsequent worsening of their catalytic activity [10]. Therefore, various new synthetic procedures have been proposed to overcome these limits $[42,43]$.

In this study, we propose a one-step strategy based on sacrificial anode electrolysis (SAE) to synthesize stabilized Pd NPs [44], directly deposited on the surface of sol-gel pre-synthesized $\mathrm{ZnO}$ nanostructures. Further post-annealing at $550{ }^{\circ} \mathrm{C}$ to obtain $\mathrm{ZnO}$ NRs is necessary [45].

The prepared hybrid $\mathrm{Pd} @ \mathrm{ZnO}$ nanostructures are proposed as active layer in chemiresistive gas sensors for the detection of pollutant HCs. The effect of the Pd catalyst on the performance of $\mathrm{ZnO}$-based gas sensors was investigated by the comparison of the gas sensing results of pristine and Pd-modified $\mathrm{ZnO} \mathrm{NRs}$, at an operating temperature of $300{ }^{\circ} \mathrm{C}$, towards methane $\left(\mathrm{CH}_{4}\right)$, propane $\left(\mathrm{C}_{3} \mathrm{H}_{8}\right)$ and butane $\left(\mathrm{C}_{4} \mathrm{H}_{10}\right)$ at a wide range of gas concentrations (30-1000 ppm). Pd-modified ZnO NRs showed a higher selectivity and sensitivity compared to pristine $\mathrm{ZnO}$ NRs. Moreover, the mean sensitivity of Pd@ZnO NRs towards 
the analyzed HCs gases increased with the length of the hydrocarbon chain of the target gas molecule.

Finally, the gas-sensing measurements towards interfering gaseous pollutants (e.g., $\mathrm{NO}_{2}$ ) revealed that the presence of $\mathrm{Pd}$ NPs on the surface of $\mathrm{ZnO}$ improves the selectivity in the detection of specific gaseous molecules. Specifically Pd@ZnO chemiresistors showed a high selectivity towards HCs compared to the pristine $\mathrm{ZnO}$-based gas sensors. On the contrary, high selectivity towards $\mathrm{NO}_{2}$ gas detection was obtained by using pristine $\mathrm{ZnO}$ chemiresistors.

\section{Experimental}

\section{Sol-gel synthesis of $\mathrm{ZnO}$}

$\mathrm{ZnO}$ nanostructures were prepared via a sol-gel process following the procedure reported in [45]. The subsequent washing of the obtained gel led to the complete removal of chlorine ions in the liquid phase. Finally, a thermal treatment at $120^{\circ} \mathrm{C}$ for $2 \mathrm{~h}$ allowed us to maintain hydroxyl $(-\mathrm{OH})$ groups on the oxide surface in order to permit the attachment of Pd NPs during the electrochemical deposition process [45].

\section{Electrochemical decoration of $\mathrm{ZnO}$ by $\mathrm{Pd}$ NPs}

$\mathrm{Pd} @ \mathrm{ZnO}$ nanostructures were prepared by SAE as reported in [44], but in this case Pd foils were used as anode (working electrode) to obtain colloidal Pd NPs. Tetraoctylammonium bromide (TOAB) was simultaneously used as electrolyte and stabilizer for Pd NPs, at a concentration of $0.05 \mathrm{M}$ in $5 \mathrm{~mL}$ in a solution of tetrahydrofurane (THF)/acetonitrile (ACN) (3:1 ratio).

Electrolysis was performed following the experimental conditions reported in [46]. Further, Pd@ZnO nanostructures were centrifuged $(6000 \mathrm{rpm})$ to separate the unsupported colloidal Pd NPs from the heavier Pd@ZnO hybrid systems. Subsequently, unfunctionalized $\mathrm{ZnO}$ and $\mathrm{Pd} @ \mathrm{ZnO}$ hybrids were annealed at $550{ }^{\circ} \mathrm{C}$ for $2 \mathrm{~h}$ in air to obtain pristine and Pd-modified rod-like $\mathrm{ZnO}$ NRs.

\section{Material characterization}

The chemical characterization of the surface of pristine and functionalized $\mathrm{ZnO}$ NRs was performed by a Thermo VG Theta Probe XPS spectrometer, using a micro-spot monochromatic Al $\mathrm{K} \alpha$ source in a fixed analyzer transmission mode. The survey spectrum was acquired with $150 \mathrm{eV}$ pass energy, and high-resolution spectra with $100 \mathrm{eV}$ pass energy. The reproducibility was evaluated replicating the analysis in five different points on each sample.

TEM (FEI TECNAI T12 TEM instrument operated at $120 \mathrm{KV}$ ) and SEM (field emission Zeiss IIGMA SEM operated at
5-10 KV, $10 \mu \mathrm{m}$ aperture) analyses were performed to evaluate the morphology of pristine and Pd-modified $\mathrm{ZnO}$ composites.

\section{Preparation of chemiresistive sensors and gas-sensing set-up}

Figure 1 shows the scheme of the used Pd-modified rod-like ZnO-based chemiresistive gas sensor.

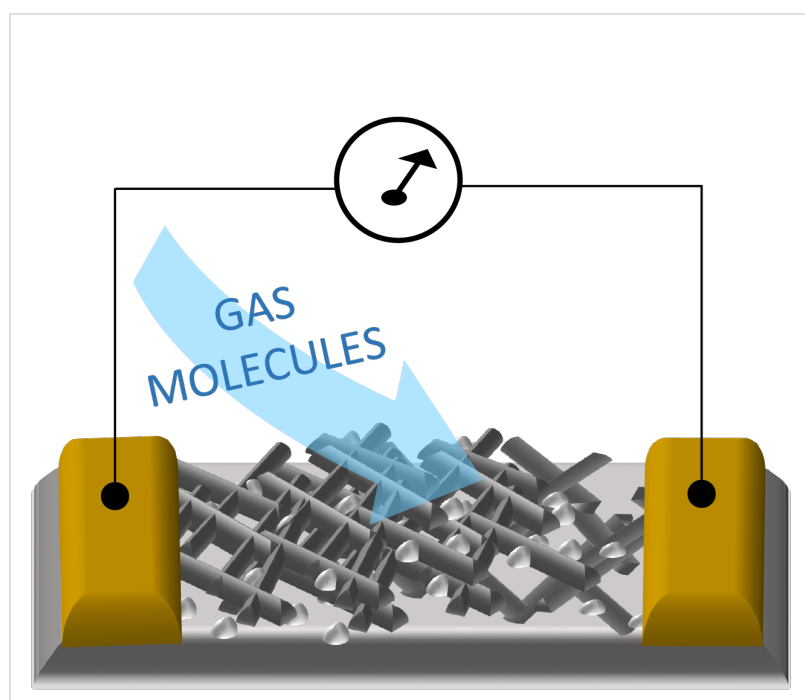

Figure 1: A scheme of a Pd-modified rod-like ZnO-based chemiresistive gas sensor.

After the annealing at $550{ }^{\circ} \mathrm{C}$, pristine and Pd-modified $\mathrm{ZnO}$ were redispersed in ACN and drop-cast on alumina substrates to obtain sensing layers between gold contacts. These assemblies were subsequently thermally stabilized at $300^{\circ} \mathrm{C}$ for $2 \mathrm{~h}$. The description of the used experimental set-up for gas sensing analyses is reported elsewhere [47]. The reference and the carrier gas, used to dilute the gaseous analyte keeping the total flow constant at $1000 \mathrm{sccm}$, was dry air. The gas sensing measurements were performed by evaluating the resistance variation of the active layer during the exposure to the analyte gas at a sensor temperature of $300^{\circ} \mathrm{C}$. Each sensing cycle consisted of an initial step of $60 \mathrm{~min}$ to stabilize the sensor signal under the reference gas, the exposure to decreasing concentrations of the target gas for $10 \mathrm{~min}$. (For the gas response measured after 2 months to evaluate the sensor stability over time and a possible effect of exposure time, the exposure time was $20 \mathrm{~min}$.) The exposure steps were separated by $30 \mathrm{~min}$ of recovery to restore the signal to the initial value and to clean the sensor surface under the reference gas flow. The response and recovery times were defined as the time needed to reach $90 \%$ of the resistance saturation value under the exposure to the analyzed gas and the time needed to recover $10 \%$ of the original resistance value in air after the exposure to the gas, respectively. 
The sensor response is reported as $\Delta R / R_{\mathrm{i}}(\%)$, and the mean gas sensitivity, $S_{\mathrm{m}}\left(\% \cdot \mathrm{ppm}^{-1}\right)$, is defined as the weighted mean of relative change of resistance (\%) divided by gas concentration unit (ppm) [45].

\section{Results and Discussion Chemical and structural properties}

The chemical composition of the surface of pristine and Pd-modified ZnO NRs was evaluated by XPS analysis. In Figure 2 the high-resolution XPS spectra of $\mathrm{Zn} 2 \mathrm{p}$ and $\mathrm{O} 1 \mathrm{~s}$ in pristine $\mathrm{ZnO}$, and of $\mathrm{Pd} 3 \mathrm{~d}$ in $\mathrm{Pd} @ \mathrm{ZnO}$ hybrid structures are reported.

High-resolution XPS Zn 2p and O 1s spectra are the same in pristine and functionalized $\mathrm{ZnO}$. Moreover, in both cases, the relative area of the two components of the $\mathrm{O} 1 \mathrm{~s}$ spectrum, $\mathrm{O}-\mathrm{Zn}$ and $\mathrm{O}-\mathrm{C}$, remains unchanged after the surface functionalization. Therefore, the atomic ratio $\mathrm{O}-\mathrm{Zn} / \mathrm{Zn}$ (the percentage of oxygen bound to metal divided by the total metal percentage) remained stoichiometric, i.e. equal to 1 , also after the metal decoration, as reported in Table 1.

In $\mathrm{Pd} @ \mathrm{ZnO}$, the presence of palladium confirmed the successful electrochemical decoration of $\mathrm{ZnO}$ nanostructures. The Pd $3 \mathrm{~d}$ high-resolution XPS spectrum is reported in Figure 2. The signal is composed of two doublets. The first one, $\mathrm{Pd} 3 \mathrm{~d}_{5 / 2}$, at $335.3 \pm 0.1 \mathrm{eV}$, was attributed to nanostructured elemental palladium [46]. The second doublet, $\mathrm{Pd} 3 \mathrm{~d}_{5 / 2}$ at $337.0 \pm 0.1 \mathrm{eV}$, was
Table 1: XPS surface chemical composition of pristine and Pd-functionalized $\mathrm{ZnO} \mathrm{NRs}$, annealed at $550{ }^{\circ} \mathrm{C}$. The value for $\mathrm{O}-\mathrm{Zn}$ refers to the atomic percentage of oxygen bound to zinc.

\begin{tabular}{lll} 
& $\mathrm{ZnO}$ & $\mathrm{Pd} @ \mathrm{ZnO}$ \\
\hline $\mathrm{C}$ & $15.7 \% \pm 0.5 \%$ & $13.5 \% \pm 0.5 \%$ \\
$\mathrm{O}_{\text {(total) }}$ & $44.5 \% \pm 0.5 \%$ & $44.5 \% \pm 0.5 \%$ \\
$\mathrm{O}-\mathrm{Zn}$ & $39.6 \% \pm 0.5 \%$ & $40.9 \% \pm 0.5 \%$ \\
$\mathrm{Zn}$ & $39.8 \% \pm 0.5 \%$ & $41.0 \% \pm 0.5 \%$ \\
$\mathrm{Pd}$ & - & $1.0 \% \pm 0.2 \%$
\end{tabular}

attributed to $\mathrm{Pd}(\mathrm{II})$ species, probably due to the presence of low amounts of $\mathrm{PdO}$ at $336.5 \pm 0.1 \mathrm{eV}$ [46].

Table 1 reports the surface atomic percentages of pristine and Pd-functionalized $\mathrm{ZnO} N R s$ after annealing at $550{ }^{\circ} \mathrm{C}$. The total amount of palladium deposited on $\mathrm{ZnO}$ was about 1.0 atom $\%$. The TOAB surfactant was almost completely removed from the Pd surface after annealing.

In Figure 3, the SEM images of pristine and Pd-functionalized $\mathrm{ZnO}$ NRs after thermal annealing at $550{ }^{\circ} \mathrm{C}$ are reported. Pristine and functionalized $\mathrm{ZnO}$ reveal a rod-like shape with an average diameter of about $30 \mathrm{~nm}$ and length of about $500 \mathrm{~nm}$. In the case of modified $\mathrm{ZnO}$, single Pd NPs of about $15 \mathrm{~nm}$ in diameter are evident on the NR surface, as reported also in the TEM inset of Figure 3B, confirming the successful electrochemical functionalization of $\mathrm{ZnO} \mathrm{NRs}$.
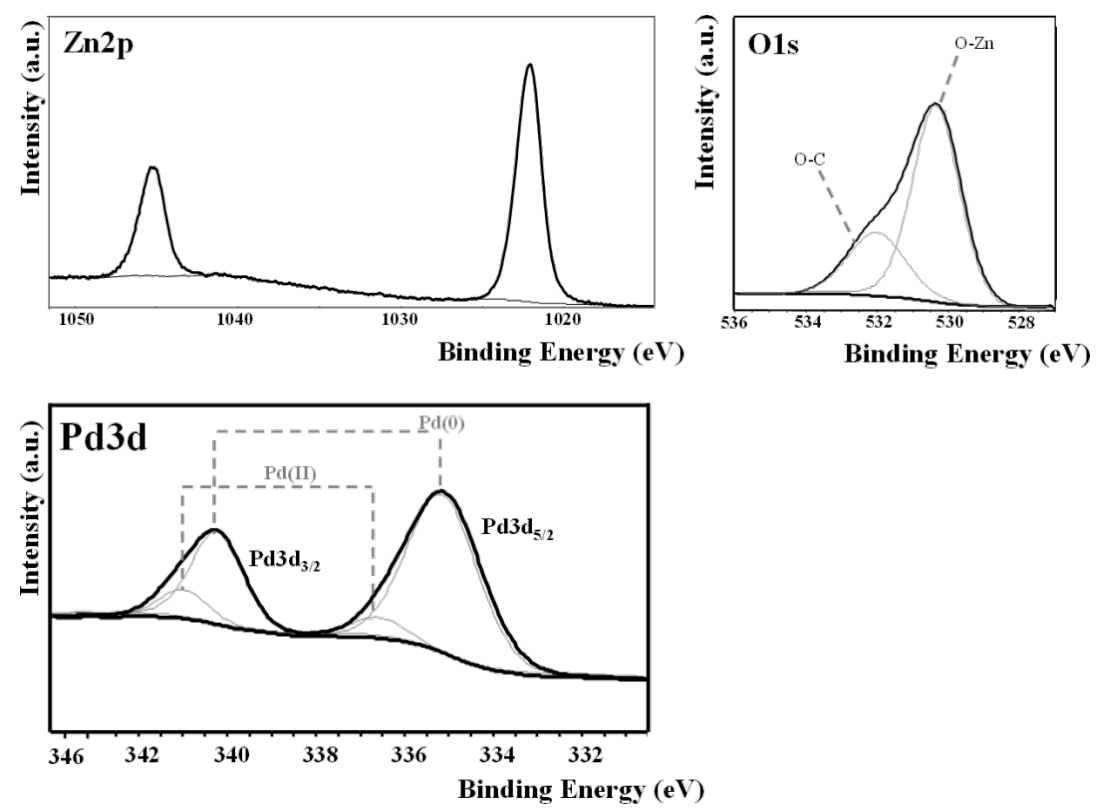

Figure 2: XPS spectra of the chemical elements in pristine $\mathrm{ZnO}: \mathrm{Zn} 2 \mathrm{p}$ and $\mathrm{O}$ 1s spectra, deconvoluted in two components (O-Zn and O-C), with the additional Pd 3d spectrum in Pd@ZnO. 

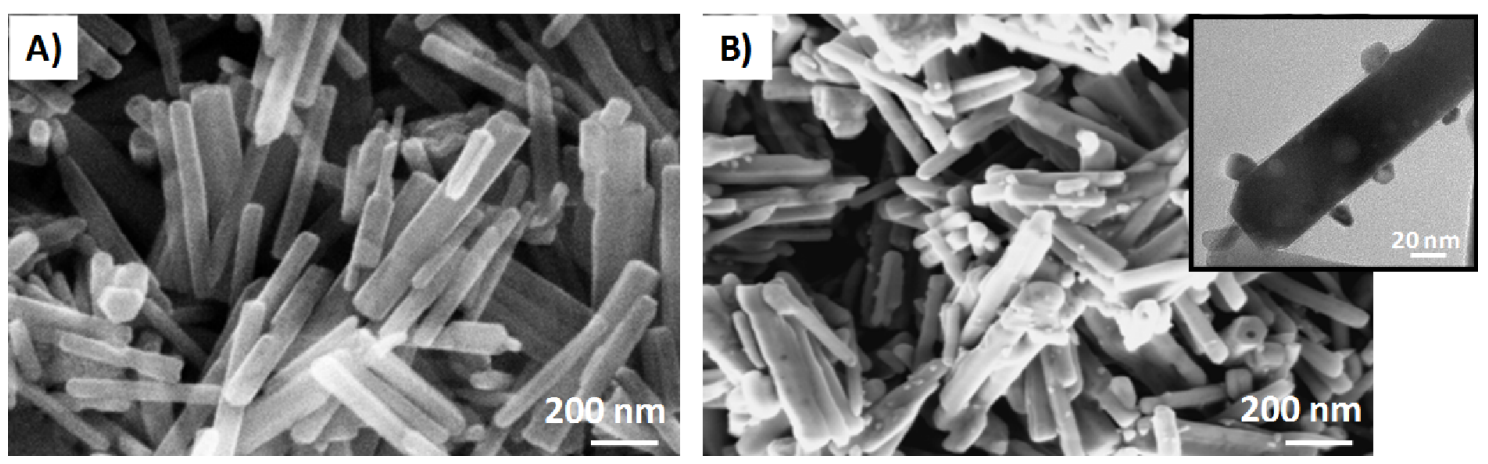

Figure 3: SEM images of A) pristine and B) Pd-modified ZnO nanostructures, after thermal annealing at $550{ }^{\circ} \mathrm{C}$. The inset shows the TEM image of Pd@ZnO NRs.

The presence of Pd NPs on ZnO NRs strongly affects gas adsorption and reactivity and, hence, the gas sensing as discussed in the following section.

\section{Gas-sensing performance}

Figure 4A shows the time responses of the electrical resistance of chemiresistors based on pristine and $\mathrm{Pd}$-modified $\mathrm{ZnO}$ NRs to various concentrations $(30-1000 \mathrm{ppm})$ of butane $\left(\mathrm{C}_{4} \mathrm{H}_{10}\right)$ at an operating temperature of $300^{\circ} \mathrm{C}$.

When pristine and $\mathrm{Pd} @ \mathrm{ZnO}$-based gas sensors are exposed to butane gas, the sensor response, the change of electrical resistance, of the hybrid sensing layers is about one order of magnitude higher than that of unmodified ZnO NRs. All films show an n-type behavior. Therefore the electrical resistance decreases in the presence of a reducing gas such as $\mathrm{C}_{4} \mathrm{H}_{10}$. The sensor responses increase upon increasing $\mathrm{C}_{4} \mathrm{H}_{10}$ gas concentration, recovering completely to the initial value after the removal of $\mathrm{C}_{4} \mathrm{H}_{10}$ gas in the test cell. As reported in the calibration curves in Figure 4B, the sensing response of pristine and Pd-modified
$\mathrm{ZnO}$ were strongly influenced by the presence of Pd catalyst on the surface of $\mathrm{ZnO}$ NRs.

In Figure 5, the sensing responses of pristine and Pd-modified $\mathrm{ZnO}$ towards butane at different concentrations (30-1000 ppm), as prepared $\left(t_{0}\right)$ and after a period of two months, were compared. Good reproducibility and stability of the gas sensors over the time are revealed.

In Table 2 the response and recovery times of pristine and Pd-modified $\mathrm{ZnO}$ NRs at different butane concentrations are reported.

Over the whole investigated concentration range the response and recovery processes were faster on Pd-modified $\mathrm{ZnO}$ NRs. This behavior can be attributed to the presence of Pd NPs, which catalyze the sensing process. Moreover, the response time was faster than the recovery time, in both cases, Pd-modified and pristine $\mathrm{ZnO}$ NRs. This is probably because the gas molecules adsorb more quickly on the surface of the sensing

\section{A)}

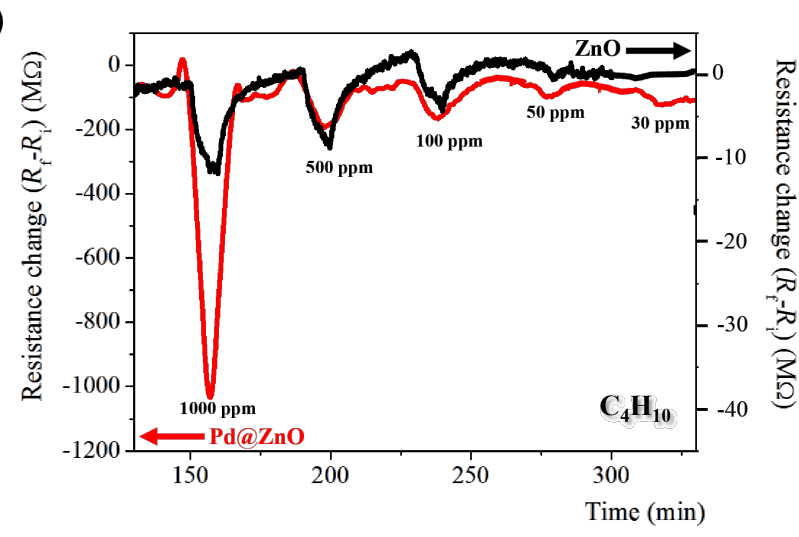

B)

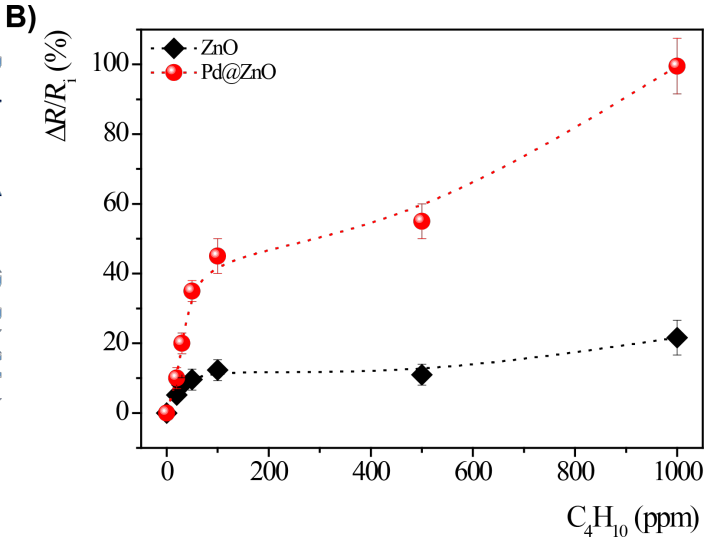

Figure 4: A) Time response and B) calibration curves of the change of electrical resistance of chemiresistors based on pristine and Pd-modified $\mathrm{ZnO}$ NRs, exposed to different concentrations $(30-1000 \mathrm{ppm})$ of butane $\left(\mathrm{C}_{4} \mathrm{H}_{10}\right)$ at an operating temperature of $300^{\circ} \mathrm{C}$. 

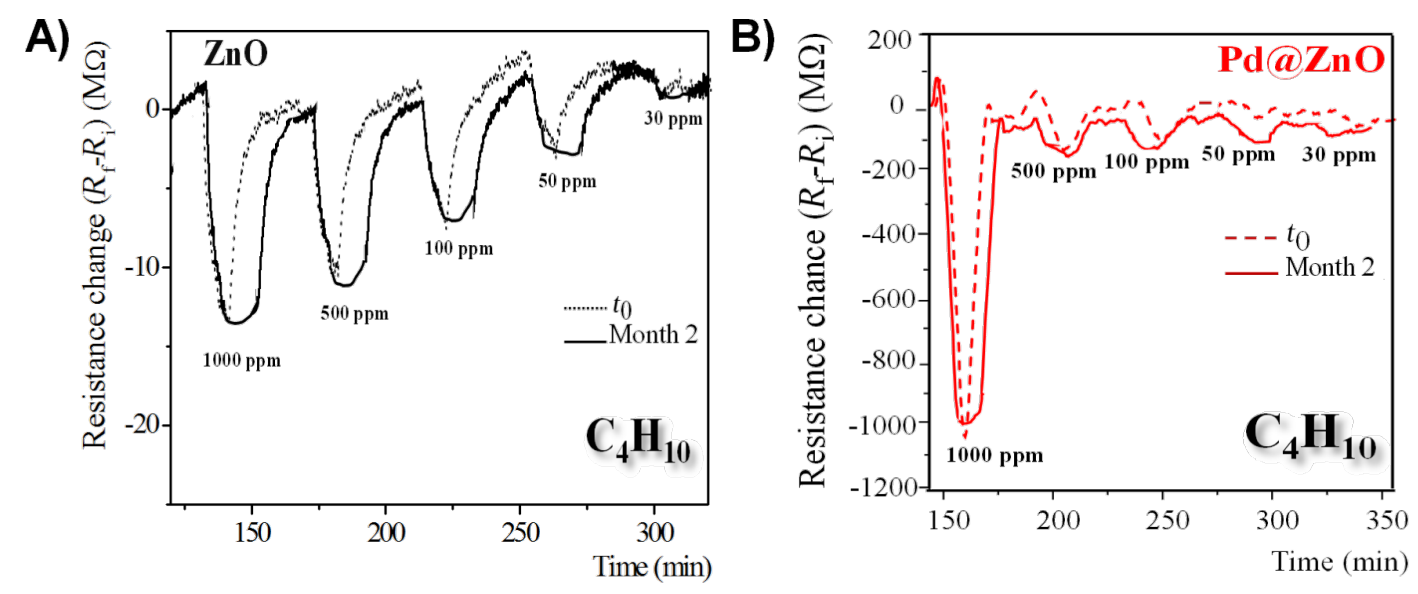

Figure 5: Time response of $\mathbf{A})$ pristine $\mathrm{ZnO}$ and $\mathbf{B}) \mathrm{Pd}$-modified $\mathrm{ZnO}$, detected at with as-prepared sensors $\left(t_{0}\right)$ and after two months, exposed to different concentrations of butane $(30-1000 \mathrm{ppm})$ at an operating temperature of $300{ }^{\circ} \mathrm{C}$.

\begin{tabular}{|c|c|c|c|c|}
\hline \multirow[b]{2}{*}{$c\left(\mathrm{C}_{4} \mathrm{H}_{10}\right)(\mathrm{ppm})$} & \multicolumn{2}{|c|}{$t_{\text {response }}(\mathrm{s})$} & \multicolumn{2}{|c|}{$t_{\text {recovery }}(\mathrm{s})$} \\
\hline & pristine $\mathrm{ZnO}$ NRs & Pd-modified ZnO NRs & pristine $\mathrm{ZnO}$ NRs & Pd-modified ZnO NRs \\
\hline 1000 & $445 \pm 30$ & $318 \pm 30$ & $600 \pm 30$ & $355 \pm 30$ \\
\hline 500 & $495 \pm 30$ & $430 \pm 30$ & $641 \pm 25$ & $525 \pm 30$ \\
\hline 100 & $526 \pm 30$ & $450 \pm 30$ & $645 \pm 30$ & $590 \pm 30$ \\
\hline 50 & $533 \pm 30$ & $480 \pm 30$ & $700 \pm 30$ & $610 \pm 30$ \\
\hline 30 & $538 \pm 30$ & $488 \pm 30$ & $730 \pm 30$ & $668 \pm 30$ \\
\hline
\end{tabular}

layer, while the desorption of gaseous species produced in the sensing process takes longer [48]. The response/recovery times in both cases were longer than those reported in literature for similar gas sensing layers (e.g., Pd-sensitized $\mathrm{ZnO}$ nanobeads [48]). This is probably because of the lower film porosity. A high film porosity is necessary to obtain better results with this HCs gas sensing mechanism [49,50].

To evaluate and compare the cross-sensitivity of the unmodified and $\mathrm{Pd}$-modified $\mathrm{ZnO} \mathrm{NRs}$, the mean sensitivity towards methane $\left(\mathrm{CH}_{4}\right)$, propane $\left(\mathrm{C}_{3} \mathrm{H}_{8}\right)$ and butane $\left(\mathrm{C}_{4} \mathrm{H}_{10}\right)$ gases at an operating temperature of $300{ }^{\circ} \mathrm{C}$ is reported in Figure 6.

The mean sensitivity of Pd-modified ZnO NRs is always higher than that of pristine $\mathrm{ZnO}$ for all analyzed HC gases. Pd NPs have a positive catalytic effect on $\mathrm{HC}$ gas sensing. Moreover, for both pristine and Pd-modified $\mathrm{ZnO}$ NRs, the mean sensitivity increases with the length of the chain length of the hydrocarbon gas. This trend can be explained by the fact that hydrocarbons with longer alkane chains have a higher surface area exposed to the sensing layer [51]. This promotes the gas adsorption process, which is the crucial step in the gas sensing [50].

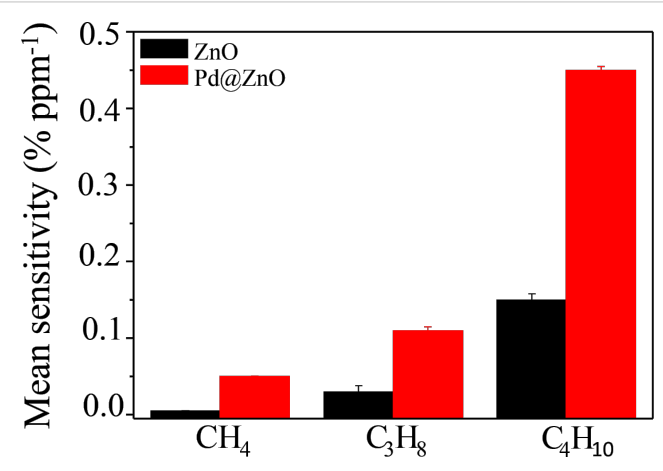

Figure 6: Mean sensitivity of pristine and $\mathrm{Pd@ZnO}$ towards $\mathrm{CH}_{4}$, $\mathrm{C}_{3} \mathrm{H}_{8}$, and $\mathrm{C}_{4} \mathrm{H}_{10}$ gases at an operating temperature of $300{ }^{\circ} \mathrm{C}$.

The enhanced response of the Pd@ZnO NRs can be attributed to the formation of highly reactive species as reported in the following reaction [52]:

$$
\mathrm{O}_{2}+\mathrm{Pd}_{2} \rightarrow 2 \mathrm{Pd}: \mathrm{O}
$$

The weak complex formed between Pd atoms and oxygen molecules quickly dissociates producing oxygen atoms that migrate along the surface of $\mathrm{ZnO}$ grains. This migration, catalyzed by 
$\mathrm{Pd}$ atoms is well known as spillover of the gas ions. In this way, the oxygen atoms capture electrons from the surface of $\mathrm{ZnO}$ and, at the same time, acceptor surface states are formed [40]. The reducing gases react with oxygen on the surface, lowering the electrical resistance of $\mathrm{ZnO}$. In presence of a great number of oxygen species, more reactions take place. The gaseous HC molecules exposed to Pd-modified $\mathrm{ZnO}$ NRs react with adsorbed oxygen in the same manner as described in Equation 1. Thus, the sensitivity towards HC gases can be improved by Pd NP catalysts deposited onto ZnO NR surface.

To evaluate the sensor selectivity, the mean sensitivity of pristine and Pd-modified $\mathrm{ZnO}$ NRs towards nitrogen dioxide and butane, at an operating temperature of $300{ }^{\circ} \mathrm{C}$, is reported in Figure 7. In $\mathrm{NO}_{2}$ gas sensing, the pristine $\mathrm{ZnO}$ NRs show a higher response. In contrast, the presence of the Pd NPs on the $\mathrm{ZnO}$ NRs improves the selectivity towards $\mathrm{C}_{4} \mathrm{H}_{10}$.

In Figure 7, butane gas has been selected to represent all investigated HCs, since the sensor response towards it is the highest of all investigated HC gases. Then, the high selectivity of Pd@ZnO-based gas sensor towards butane gas can be extended to all $\mathrm{HCs}$ gas in presence of $\mathrm{NO}_{2}$ gas. The catalytic effect of $\mathrm{Pd}$ NPs positively affects the sensing of reducing HCs gases and lowers the detection of oxidizing $\mathrm{NO}_{2}$ gas.

When measuring a mixture of HCs gases, since the resistance variation for all investigated HCs is the same, this sensor system does not permit to distinguish the type of HC gas, producing a sum result as sensor response. To overcome this problem a multiplexed array of differently functionalized sensing materials could be used, in which each sensor system is selective in the detection of a specific gas.

\section{Conclusion}

The successful electrochemical functionalization of $\mathrm{ZnO}$ NRs by Pd NPs is reported. The gas sensing properties of pristine and Pd-modified rod-like $\mathrm{ZnO}$-based chemiresistor revealed that the presence of catalytic Pd NPs on the surface of ZnO NRs improves the sensitivity and selectivity towards the detection of HCs gases at an operating temperature of $300{ }^{\circ} \mathrm{C}$.

Future work will be addressed to evaluate the sensing properties of electrochemically functionalize $\mathrm{ZnO}$ NRs with noble metals (e.g. Au and Pd), used as sensing layer in chemiresistive gas sensors, to improve their sensitivity and selectivity towards other toxic and polluting gases.

\section{Acknowledgements}

The authors thank the COST Action TD1105 EuNetAir for the international networking activities in the field of the sensor materials for air-pollution monitoring. The authors also thank the Italian Ministry of University and Scientific Research, PON program 2007-2013 for financial support, specifically PON02_00576_3333604 “INNOVHEAD” project.

\section{References}

1. Technical Overview of Volatile Organic Compounds. https://www.epa.gov/indoor-air-quality-iaq/technical-overview-volatile-or ganic-compounds (accessed Aug 21, 2016).

2. Davis, J. B.; Squire, R. M. Science 1954, 119, 381-382. doi:10.1126/science.119.3090.381

3. Fujio, Y.; Plashnitsa, V. V.; Elumalai, P.; Miura, N. Talanta 2011, 85, 575-581. doi:10.1016/j.talanta.2011.04.024

4. Bajtarevic, A.; Ager, C.; Pienz, M.; Klieber, M.; Schwarz, K.; Ligor, M.; Ligor, T.; Filipiak, W.; Denz, H.; Fiegl, M.; Hilbe, W.; Weiss, W.; Lukas, P.; Jamnig, H.; Hackl, M.; Haidenberger, A.; Buszewski, B.; Miekisch, W.; Schubert, J.; Amann, A. BMC Cancer 2009, 9, 348-364. doi:10.1186/1471-2407-9-348

5. Ligor, M.; Ligor, T.; Bajtarevic, A.; Ager, C.; Pienz, M.; Klieber, M.; Denz, H.; Fiegl, M.; Hilbe, W.; Weiss, W.; Lukas, P.; Jamnig, H.; Hackl, M.; Buszewski, B.; Miekisch, W.; Schubert, J.; Amann, A. Clin. Chem. Lab. Med. 2009, 47, 550-560. doi:10.1515/CCLM.2009.133

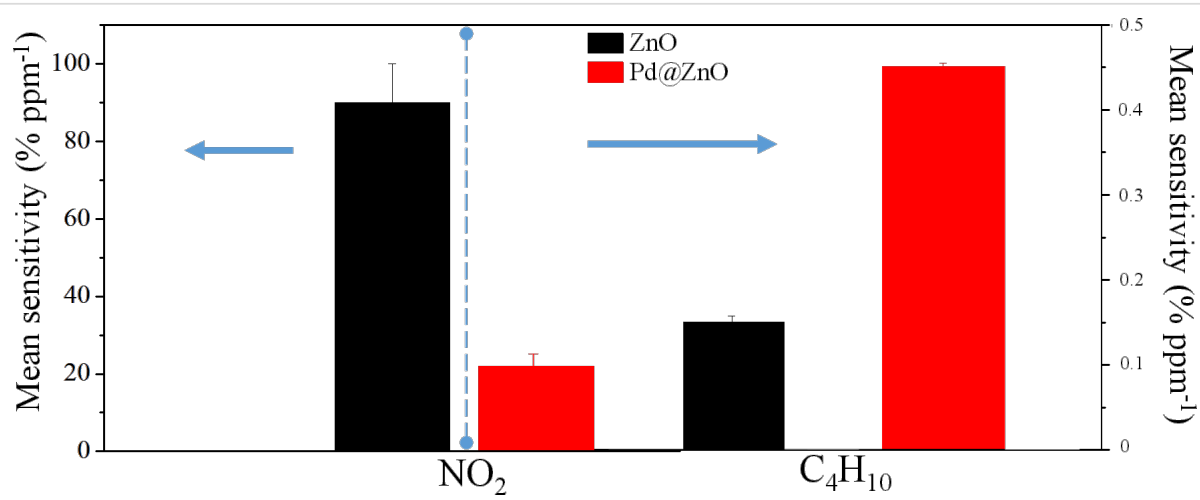

Figure 7: Mean sensitivity of pristine and $\mathrm{Pd} @ \mathrm{ZnO}$ NRs towards $\mathrm{NO}_{2}$ and $\mathrm{C}_{4} \mathrm{H}_{10}$ at an operating temperature of $300{ }^{\circ} \mathrm{C}$. 
6. Rhoderick, G. C.; Duewer, D. L.; Apel, E.; Baldan, A.; Hall, B.; Harling, A.; Helmig, D.; Heo, G. S.; Hueber, J.; Kim, M. E.; Kim, Y. D.; Miller, B.; Montzka, S.; Riemer, D. Anal. Chem. 2014, 86, 2580-2589. doi:10.1021/ac403761u

7. Giang, H. T.; Duy, H. T.; Ngan, P. Q.; Thai, G. H.; Thu, D. T. A.; Thu, D. T.; Toan, N. N. Sens. Actuators, B 2011, 158, 246-251. doi:10.1016/j.snb.2011.06.013

8. Wilk, A.; Carter, J. C.; Chrisp, M.; Manuel, A. M.; Mirkarimi, P.; Alameda, J. B.; Mizaikoff, B. Anal. Chem. 2013, 85, 11205-11210. doi:10.1021/ac402391m

9. Brigo, L.; Michieli, N.; Artiglia, L.; Scian, C.; Rizzi, G. A.; Granozzi, G.; Mattei, G.; Martucci, A.; Brusatin, G. ACS Appl. Mater. Interfaces 2014, 6, 7773-7781. doi:10.1021/am501042f

10. Ho, C. K.; Hughes, R. C. Sensors 2002, 2, 23-34. doi:10.3390/s20100023

11. Lu, C.-J.; Whiting, J.; Sacks, R. D.; Zellers, E. T. Anal. Chem. 2003, 75, 1400-1409. doi:10.1021/ac026092n

12. Hennig, O.; Strzoda, R.; Mágori, E.; Chemisky, E.; Tump, C.; Fleischer, M.; Meixner, H.; Eisele, I. Sens. Actuators, B 2003, 95, 151-156. doi:10.1016/S0925-4005(03)00399-X

13. Sahner, K.; Hagen, G.; Schönauer, D.; Reiß, S.; Moos, R. Solid State lonics 2008, 179, 2416-2423. doi:10.1016/j.ssi.2008.08.012

14. Product overview: Leopold Siegrist $\mathrm{GmbH}$. http://www.siegrist.de/en/product-overview.html (accessed Aug 21, 2016).

15. Blair, R.; Shepherd, H.; Faltens, T.; Haussmann, P. C.; Kaner, R. B.; Tolbert, S. H.; Huang, J.; Virji, S.; Weiller, B. H. J. Chem. Educ. 2008, 85, 1102. doi:10.1021/ed085p1102

16. Xie, D.; Jiang, Y.; Pan, W.; Li, D.; Wu, Z.; Li, Y. Sens. Actuators, B 2002, 81, 158-164. doi:10.1016/S0925-4005(01)00946-7

17. Jun, H.-K.; Hoh, Y.-S.; Lee, B.-S.; Lee, S.-T.; Lim, J.-O.; Lee, D.-D.; Huh, J.-S. Sens. Actuators, B 2003, 96, 576-581. doi:10.1016/j.snb.2003.06.002

18. Chang, J. B.; Liu, V.; Subramanian, V.; Sivula, K.; Luscombe, C.; Murphy, A.; Liu, J.; Fréchet, J. M. J. J. Appl. Phys. 2006, 100, 014506. doi:10.1063/1.2208743

19. Bianco, S., Ed. Carbon Nanotubes - From Research to Applications; InTech, 2011. doi:10.5772/981

20. Wang, T.; Huang, D.; Yang, Z.; Xu, S.; He, G.; Li, X.; Hu, N.; Yin, G.; He, D.; Zhang, L. Nano-Micro Lett. 2016, 8, 95. doi:10.1007/s40820-015-0073-1

21. Bai, H.; Shi, G. Sensors 2007, 7, 267-307. doi:10.3390/s7030267

22. Inzelt, G. Applications of Conducting Polymers. Conducting Polymers; Springer: Berlin, Germany, 2012; pp 245-293. doi:10.1007/978-3-642-27621-7_7

23. Janata, J.; Josowicz, M. Nat. Mater. 2003, 2, 19-24. doi:10.1038/nmat768

24. Wang, X.; Ugur, A.; Goktas, H.; Chen, N.; Wang, M.; Lachman, N.; Kalfon-Cohen, E.; Fang, W.; Wardle, B. L.; Gleason, K. K. ACS Sens. 2016, 1, 374-383. doi:10.1021/acssensors.5b00208

25. Williams, D. E. Sens. Actuators, B 1999, 57, 1-16 doi:10.1016/S0925-4005(99)00133-1

26. Meixner, H.; Lampe, U. Sens. Actuators, B 1996, 33, 198-202. doi:10.1016/0925-4005(96)80098-0

27. Niranjan, R. S.; Sainkar, S. R.; Vijayamohanan, K.; Mulla, I. S. Sens. Actuators, B 2002, 82, 82-88. doi:10.1016/S0925-4005(01)00994-7
28. Vilaseca, M.; Coronas, J.; Cirera, A.; Cornet, A.; Morante, J. R.; Santamaria, J. Catal. Today 2003, 82, 179-185. doi:10.1016/S0920-5861(03)00230-X

29. Trimboli, J.; Dutta, P. K. Sens. Actuators, B 2004, 102, 132-141. doi:10.1016/j.snb.2004.03.006

30. Tamaki, J.; Mishima, K.; Fujimori, H.; Udaka, T. Chem. Sens. 2003, 19, 214-216.

31. Dubbe, A.; Moos, R. Electrochem. Solid-State Lett. 2006, 9, H31-H34. doi:10.1149/1.2181292

32. Hagen, G.; Dubbe, A.; Rettig, F.; Jerger, A.; Birkhofer, T.; Müller, R.; Plog, C.; Moos, R. Sens. Actuators, B 2006, 119, 441-448. doi:10.1016/j.snb.2005.12.052

33. Srivastava, A. K.; Dravid, V. P. Sens. Actuators, B 2006, 117, 244-252. doi:10.1016/j.snb.2005.11.034

34. Liu, L.; Zhang, Y.; Wang, G.; Li, S.; Wang, L.; Han, Y.; Jiang, X.; Wei, A. Sens. Actuators, B 2011, 160, 448-454. doi:10.1016/j.snb.2011.08.007

35. Tian, S.; Yang, F.; Zeng, D.; Xie, C. J. Phys. Chem. C 2012, 116, 10586-10591. doi:10.1021/jp2123778

36. Chu, J.; Peng, X.; Sajjad, M.; Yang, B.; Feng, P. X. Thin Solid Films 2012, 520, 3493-3498. doi:10.1016/j.tsf.2011.12.066

37. Zhang, Y.; Zheng, Z.; Yang, F. Ind. Eng. Chem. Res. 2010, 49, 3539-3543. doi:10.1021/ie100197b

38. Kanan, S. M.; El-Kadri, O. M.; Abu-Yousef, I. A.; Kanan, M. C. Sensors 2006, 9, 8158-8196. doi:10.3390/s91008158

39. Sivapunniyam, A.; Wiromrat, N.; Myint, M. T. Z.; Dutta, J. Sens. Actuators, B 2011, 157, 232-239. doi:10.1016/j.snb.2011.03.055

40. Gurav, K. V.; Deshmukh, P. R.; Lokhande, C. D. Sens. Actuators, B 2011, 151, 365-369. doi:10.1016/j.snb.2010.08.012

41. Sahner, K.; Moos, R.; Matam, M.; Tunney, J. J.; Post, M. Sens. Actuators, B 2005, 108, 102-112. doi:10.1016/j.snb.2004.12.104

42. Kobayashi, Y.; Ishii, Y.; Yamane, H.; Watanabe, K.-i.; Koda, H.; Kunigami, H.; Kunigami, H. Colloids Surf., A 2014, 448, 88-92. doi:10.1016/j.colsurfa.2014.02.018

43. Lim, M. A.; Kim, D. H.; Park, C.-O.; Lee, Y. W.; Han, S. W.; Li, Z.; Wiliams, R. S.; Park, I. ACS Nano 2012, 6, 598-698. doi:10.1021/nn204009m

44. Reetz, M. T.; Helbig, W. J. Am. Chem. Soc. 1994, 116, 7401-7402. doi:10.1021/ja00095a051

45. Dilonardo, E.; Penza, M.; Alvisi, M.; Di Franco, C.; Palmisano, F.; Torsi, L.; Cioffi, N. Beilstein J. Nanotechnol. 2016, 7, 22-31. doi:10.3762/bjnano.7.3

46. Cioffi, N.; Torsi, L.; Losito, I.; Sabbatini, L.; Zambonin, P. G.; Bleve-Zacheo, T. Electrochim. Acta 2001, 46, 4205-4211. doi:10.1016/S0013-4686(01)00700-9

47. Penza, M.; Rossi, R.; Alvisi, M.; Serra, E. Nanotechnology 2010, 21 , 105501. doi:10.1088/0957-4484/21/10/105501

48. Shinde, V. R.; Gujar, T. P.; Lokhande, C. D. Sens. Actuators, B 2007, 123, 701-706. doi:10.1016/j.snb.2006.10.003

49. Gómez-Pozos, H.; Arredondo, E. J. L.; Álvarez, A. M.; Biswal, R.; Kudriavtsev, Y.; Pérez, J. V.; Casallas-Moreno, Y. L.; de la Luz Olvera Amador, M. Materials 2016, 9, 87-103. doi:10.3390/ma9020087

50. Basu, S.; Basu, P. K. J. Sens. 2009, 2009, No. 861968. doi:10.1155/2009/861968

51. Marr, I.; Reiß, S.; Hagen, G.; Moos, R. Sensors 2011, 11, 7736-7748. doi:10.3390/s110807736

52. Nenov, T. G.; Yordanov, S. P. Ceramics Sensors, Technology and Applications; Technomic: Lancaster, United Kingdom, 1996. 


\section{License and Terms}

This is an Open Access article under the terms of the Creative Commons Attribution License

(http://creativecommons.org/licenses/by/4.0), which permits unrestricted use, distribution, and reproduction in any medium, provided the original work is properly cited.

The license is subject to the Beilstein Journal of Nanotechnology terms and conditions:

(http://www.beilstein-journals.org/bjnano)

The definitive version of this article is the electronic one which can be found at:

doi:10.3762/bjnano.8.9 